\title{
HUBUNGAN TINGKAT PENGETAHUAN TERHADAP PERILAKU SWAMEDIKASI OBAT ANTINYERI DI KECAMATAN ULUJAMI KABUPATEN PEMALANG
}

\author{
RELATIONSHIP LEVEL OF KNOWLEDGE TO \\ ANTI PAIN DRUG SWAMEDICATION BEHAVIOR \\ ULUJAMI DISTRICT, PEMALANG REGENCY
}

\author{
Opi Nuriska Ra' is ${ }^{1}$, Ainun Muthoharoh ${ }^{2 *}$, Wulan Agustin Ningrum ${ }^{3}$, \\ Yulian Wahyu Permadi ${ }^{4}$ \\ ${ }^{1}$ Sarjana Farmasi, Universitas Muhammadiyah Pekajangan Pekalongan, Indonesia \\ Email: nuriskaopi@gmail.com
}

Submitted : 28 Agustus 2021 Reviewed : 16 September 2021 Accepted : 30 September 2021

\begin{abstract}
ABSTRAK
Nyeri merupakan sensasi yang mengindikasi bahwa tubuh sedang mengalami kerusakan jaringan, inflamasi, atau kelainan yang lebih berat seperti difungsi sistem saraf. Beberapa penelitian membuktikan bahwa tingkat pengetahuan masyarakat sangat berhubungan dengan penggunaan obat antinyeri atau analgesik secara rasional. Swamedikasi atau pengobatan sendiri merupakan upaya masyarakat untuk mengatasi nyeri yang terjadi terutama secara akut atau mendadak. Tujuan dari penelitian adalah untuk mengetahui hubungan pengetahuan terhadap perilaku swamedikasi obat anti nyeri di masyarakat pesisir Kecamatan Ulujami Kabupaten Pemalang.Penelitian ini menggunakan teknik purpose sampling. Responden diambil dengan rumus slovin berjumlah 100 sampel dengan pengambilan 20 responden untuk 1 desa. Dari hasil penelitian didapatkan data tingkat pengetahuan di Kecamatan Ulujami $85 \%$ dengan kategori cukup dan untuk perilaku swamedikasi obat anti nyeri didapatkan data sebanyak $78 \%$ dengan kategori baik. Kesimpulan dari penelitian ini bahwa tidak ada hubungan antara tingkat pengetahuan dengan perilaku swamedikasi obat anti nyeri di kalangan masyarakat sekitar pesisir Kecamatan Ulujami. Saran diharapkan untuk masyarakat sekitar pesisir lebih baik dalam penggunaan obat anti nyeri.
\end{abstract}

Kata kunci : Masyarakat Pesisir, Obat Anti Nyeri, Swamedikasi

\begin{abstract}
Pain is a sensation that indicates that the body is experiencing tissue damage, inflammation, or more severe disorders such as nervous system dysfunction. Several studies have shown that the level of public knowledge is closely related to the rational use of painkillers or analgesics. Self-medication or self-medication is an effort by the community to treat pain that occurs especially acutely or suddenly. The purpose of the study was to determine the relationship between knowledge and self-medication behavior of anti-pain medication in coastal communities in Ulujami District, Pemalang Regency. This study uses a purpose sampling technique. Respondents were taken using the slovin formula totaling 100 samples with 20 respondents for 1 village. From the results of the study, it was found that the level of knowledge in Ulujami sub-district was $85 \%$ with sufficient category and for selfmedication behavior of anti-pain drugs obtained data as much as $78 \%$ with good category. The conclusion of this study is that there is no relationship between the level of knowledge
\end{abstract}


and the behavior of self-medication of anti-pain drugs among the people around the coast of Ulujami District. Suggestions are expected for communities around the coast to be better at using anti-pain drugs.

Keywords: Coastal Communities, Anti-Pain Drugs, Self-Medication

\author{
Penulis Korespondensi : \\ Opi Nuriska Ra'is \\ Universitas Muhammadiyah Pekajangan Pekalongan, \\ Email : nuriskaopi@gmail.com
}

\title{
PENDAHULUAN
}

Analgetika adalah obat yang dapat mengurangi atau menghilangkan rasanyeri. Nyeri adalah perasaan sensoris dan emosionl yang tidak nyaman berkaitan dengan ancaman kerusakan jaringan. Rasa nyeri merupakan suatu gejala yang berfungsi sebagai isyarat tentang adanya gangguan dijaringan seperti peradangan, reumatik, encok atau kejang otot. Selain pengobatan secara farmakologi, ada juga pengobatan dengan cara non farmakologi yaitu dengan cara menempelkan kompres hangat dan menggunakan aromatrapi (Purnamasari, dkk, 2013).

Swamedikasi merupakan pengobatan sendiri terhadap suatu penyakit atau gejala yang ringan dilakukan dengan obat kimiawi maupun obat tradisioal yang dapat dibeli tanpa menggunakan resep dari dokter. Swamedikasi atau pengobatan sendiri dilakukan untuk keluhan gejala atau penyakit yang ringan dan umum dijumpai dimasyarakat, misalnya batuk, maag, influenza, diare, nyeri dan demam. Swamedikasi yang bertanggung jawab membutuhkan tingkat pengetahuan. Tingkat pengetahuan yang rendah dapat berisiko penggunaan obat yang tidak tepat dalam perilaku swamedikasi seperti yang dijelaskan oleh Lawrence Green dalam teorinya PRECEDE. Green menyatakan bahwa kesehatan seseorang atau masyarakat dipengaruhi oleh dua faktor pokok, yaitu faktor perilaku (behavior causes) dan faktor di luar perilaku (non- behavior causes). Perilaku dipengaruhi oleh tiga faktor yang dirangkum dalam akronim PRECEDE yang meliputi faktor predisposisi (redisposing factors), faktor- faktor pemungkin (enabling factors), dan faktor- faktor pendorong atau penguat (reinforcing factors) (Notoatmodjo, 2012). Semakin baik tingkat pengetahuan seseorang tentang obat anti nyeri, maka semakin positif perilaku swamedikasi obat anti nyeri (Ananda dkk, 2013). Pengetahuan merupakan faktor yang mempengaruhi perilaku dalam waktu yang lama namun bersifat langgeng karena didasari oleh kesadaran sendiri (Notoatmodjo, 2012).

Ulujami adalah salah satu kecamatan yang berada di Kabupaaten Pemalang dengan jumlah desa ada 18 desa, ulujami sendiri memilik beberapaa desa yang berada dekat dengan pesisir pantai, desa yang berada didekat pesisir ada 5 yakni Desa Tasikrejo, Desa Kaliprau, Desa Kertosari, Desa Blendung, dan Desa Limbangan, mayoritas masyarakat yang ada di pesisir pantai bermata pencaharian sebagai petani, buruh tambak ada, buruh konveksi, tingkat pendidikan untuk anak-anak dan remaja masih direntang SMP dan SMA ada juga yang hanya bertamatkan SD, hal ini terjadi karena masih banyak masyarakat yang berfikir bahwa tidak ada gunanya menyekolahkan anak sampai kejenjang sarjana dengan begitu banyak anak-anak yang sudah diajari bekerja kasar di lingkungan sekitar seperti buruh jahit, kuli bangunan dan juga menjadi buruh-buruh lainnya. Berdasarkan latar belakang yang telah diuraikan maka peneliti ingin mengetahui adakah hubungan antara tingkat pengetahuan dengan swamedikasi anti nyeri untuk masyarakat pesisir Kecamtan Ulujami Kabupaten Pemalang.

Tujuan umum untuk mengetahui hubungan pengetahuan terhadap perilaku swamedikasi obat anti nyeri di masyarakat sekitar pesisir Kecamatan Ulujami Kabupaten Pemalang. Tujuan Khusus dalam penelitian ini yang pertama mengetahui ketepatan perilaku swamedikasi obat anti nyeri yang dilakukan oleh masyarakat sekitar pesisir Keamatan 
Ulujami Kabupaten Pemalang, yang kedua untukmengetahui tingkat pengetahuan masyarakat sekitar pesisir Kecamatan Ulujami Kabupaten Pemalang terhadap obat anti nyeri.

\section{METODE PENELITIAN}

Penelitian ini merupakan jenis penelitian deskriptif analitik dengan teknik purpose sampling dalam pengambilan sampel. Purpose sampling yaitu teknik penentuan sampel dengan pertimbangan tertentu (Sugiyono, 2012). Pemilihan sekelompok subjek dalam purpose sampling didasarkan kriteria inklusi yaitu sampel yang dapat dimasukkan atau layak untuk diteliti. Instrumen penelitian yang digunakan adalah kuisioner sebagai alat pengukur data dan menggunakan metode survey dilakukan pendekatan cross sectional, yaitu pengukuran atau pengamatan secara bersamaan atau sekali waktu pengambilan data.

\section{Alat dan Bahan}

Instrumen penelitian adalah alat yang digunakan dalam penelitian ini untuk pengumpulan data. Penelitian ini menggunakan kuesioner sebagai instrumen penelitian. Kuesioner adalah daftar pertanyaan yang sudah tersusun dengan baik, dimana responden tinggal memberikan jawaban atau dengan memberikan tanda-tanda tertentu. Kuesioner adalah bentuk dari penjabaran variabel-variabel yang terlibat dalam tujuan penelitian. Kuesioner yang digunakan dalam penelitian ini melihat dari kuesioner penelitian sebelumnya yang telah dimodifikasi kembali dan ada beberapa pertanyaan yang dibuat sendiri oleh peneliti yang terdiri dari 3 bagian kuesioner yaitu bagian pendahuluan, tingkat pengetahuan swamedikasi, dan perilaku swamedikasi.

Waktu dan tempat penelitian ini dilakukan di 5 desa sekitar pesisir Kecamatan Ulujami Kabupaten Pemalang. Penelitian ini dilaksanakan pada tanggal 6-10 Agustus tahun 2021.

Dalam penilitian ini sampel yang digunakan adalah masyarakat yang ada disekitar pesisir Kecamatan Ulujami Kabupaten Pemalang dengan 5 desa yang jumlah total masyarakatnya ada sebanyak 32.555 jiwadan penelitian ini dihitung dengan menggunakan rumus slovin yang dikemukan oleh Hesein Umar (2013) sebagai berikut:

$$
\begin{aligned}
& \text { Keterangan: } \\
& \mathrm{n}=\text { Jumlah sampel } \\
& \mathrm{N}=\mathrm{N} / 1+\mathrm{Ne}^{2} \\
& \mathrm{e}=\text { Bamlah populasi } \\
& \mathrm{N}=32.555 / 32.555 .(0.1) 2+1 \\
& \mathrm{~N}=99,69=100
\end{aligned}
$$

Hasil perhitungan menunjukkan bahwa jumlah minimal sampel responden yang dibutuhkan adalah sebanyak 100 orang. Pada perhitungan tersebut sampel yang hendak digunakan 100 responden dengan pengambilan responden sebanyak 20 sampel untuk 1 desa.

\section{Jalannya Penelitian}

Penelitian ini dilakukan di masyarakat desa sekitar pesisir di Kecamatan Ulujami Kabupaten Pemalang. Dalam penelitian ini ada beberapa prosedur pengumpulan data, yakni sebagai berikut:

1. Tahap persiapan dan studi pendahuluan.

a. Mengajukan judul penelitian kepada Program Studi Sarjana Farmasi Fakultas Ilmu Kesehatan Universitas Muhammadiyah Pekajangan Pekalongan 
b. Melakukan perizinan ke bagian LPPM Fakultas Ilmu Kesehatan Universitas Muhammadiyah Pekajangan Pekalongan

c. Melakukan perizinan ke kantor KESBANGPOL Kota Pemalang

d. Melakukan perizinan ke kantor BAPPEDA Kota Pemalang

e. Mendapatkan izin dan jumlah data masyarakat yang berada di pesisir Kecamatan Ulujami Kabupapten Pemalang

2. Tahap Penyusunan Proposal

a. Menyusun proposal

b. Menentukan total sampel yang memenuhi kriteria inklusi.

c. Menyusun kuesioner melalui studi pustaka

3. Tahap Uji Validitas Kuesioner

a. Melakukan perizinan uji validitas ke kantor KESBANGPOL Kota Pemalang

b. Melakukan perizinan uji validitas ke kantor BAPPEDA Kota Pemalang

c. Melakukan Pembagian Kuisioner

4. Tahap pelaksanaan dan pengolahan data

a. Melakukan perizinan penelitian ke bagian LPPM Fakultas Ilmu Kesehatan Universitas Muhammadiyah Pekajangan Pekalongan

b. Melakukan perizinan penelitian ke kantor KESBANGPOLKota Pemalang

c. Melakukan perizinan penelitian ke kantor BAPPEDA Kota Pemalang

d. Melakukan perizinan penelitian Pemerintah Kecamatan dan Desa

e. Mendapatkan izin penelitian dari Pemerintah Kecamatan dan Desa

f. Pengumpulan data dilakukan pada bulan Mei-Juni

g. Kuesioner dibagikan di 5 Desa di sekitar pesisir Kecamatan Ulujami

$\mathrm{h}$. Secara langsung dengan jumlah 100 responden yang memenuhi kriteria inklusi.

i. Responden mengisi kuesioner didampingi oleh peneliti

j. Data yang telah dikumpulkan diolah dengan menggunakan aplikasi Statistical Product and Service Solutions (SPSS) versi 16.

k. Pembuatan laporan hasil penelitian dan pembahasan.

Pengambilan kesimpulan dan saran.

\section{Analisis Data}

Analisis data dalam penelitian ini menggunakan program SPSS versi 21. Data diperoleh dari kuisioner yang telah diisi oleh responden. Data yang terkumpul kemudian dianalisis. Peneliti sebelumya membagikan daftar pertanyaan yang nantinya akan dijawab oleh responden. Daftar pertanyaan itu disebut dengan kusioner dan digunakan sebagi alat untuk mengukur variabel bebas dan variabel terikat. Sebelum digunakan kuisioner terlebih dahulu dilakukan uji validitas dan uji realibilitas.

1. Uji Validitas

Uji validitas merupakan suatu tolak ukur yang digunakan untuk megukur apakah data valid atau tidak. Untuk dapat mengetahui suatu kusioner yang disusun valid, maka dilakukan uji korelasi antara nilai atau skor dari tiap-tiap item dengan skor total kuisioner. Kusioner yang dibuat dberikan kepada responden untuk uji coba. Jumlah responden yang digunakan untuk uji validitas sebanyak 30 responden (Wibowo. 2014). Dalam penilitian ini uji validitas dilakukan di Desa Ambowetan Kecamatan Ulujami. Setelah dilakukan kemudian dihitung nilai korelasi dari skor masing-masing pertanyaan. roduct moment merupakan teknik korelasi yang digunakan untuk menghitung kolerasi dengan menggunakan SPSS. Langka-langkah yang digunkan yaitu:

a. Memasukkan data yang diperoleh.

b. Melakukan analisis kolerasi product moment yaitu analysis-correelate-bivariat.

c. Mengisi kolom variable dengan semua item, serta jumlahnya.

d. Lalu klik Ok.

\section{Uji Reabilitas}

Dalam penelitian ini uji realibilitas menggunakan aplikasi SPSS versi 16, yang diguakan adalah data yang valid. Metode batasan 0,60 merupakan metode pengambilan 
keputusan yang bertujuan untuk menentukan instrumen penelitian reilabel atau tidak reiable. Dalam metode ini dapat dilakukan dengan membandingkan nilai crobach alpha dan batasan nilai 0,60 . Bersifat reliable apabila nilaii crobach alpha kurang dari 0,6 dan apabila lebih darai 0,60 maka tidak reliabel (Priyatno, 2016).

3. Uji Korelasi

Uji korelasi digunakan untuk mengetahui tingkat keratan hubungan variabelindependen dengan variabel dependen. Dalam penelitian ini, formula yang digunakan untuk melakukan perhitungan koefisien korelasi adalah formula koefisien korelasi momen produk (Product Moment) karl pearson dengan rumus sebagai berikut:

$$
r=\frac{\sum(x-\bar{x})(y-\bar{y})}{\sqrt{\sum(x-\bar{x})^{2}} \sqrt{\sum(y-\bar{y})^{2}}}
$$

Keterangan:

$\mathrm{r}=$ Koefisien korelasi

$\mathrm{x}=$ Variabel bebas (independen)

$\mathrm{y}=$ Variabel terikat (depeden)

$\mathrm{n}=$ Jumlah yang dihitung

\section{HASIL DAN PEMBAHASAN}

Penelitian hubungan tingkat pengetahuan terhadap perilaku swamedikasi obat anti nyeri dikalangan masyarakat sekitar pesisir di Kecamatan Ulujami Kabupaten Pemalang yang dilakukan dari tanggal 6 Agustus-10 Agustus 2021, penelitian ini dilakukan dengan tujuan untuk mengetahui adanya hubungan tingkat pengetahuan terhadap perilaku swamedikasi obat anti nyeri dikalangan masyarakat sekitar pesisir Kecamatan Ulujami Kabupaten Pemalang. Penelitian ini termasuk dalam jenis penelitian deskriptif analitik dengan teknik purpose sampling, dalam pengambilan sampel purpose sampling yaitu teknik penentuan sampel didasarkan kriteria inklusi yaitu sampel yang dapat dimasukkan atau layak untuk diteliti. Instrumen penelitian yang digunakan adalah kuisioner sebagai alat pengukur data dan menggunakan metode survey dilakukan pendekatan cross sectional, yaitu pengukuran atau pengamatan secara bersamaan atau sekali waktu pengambilan data.

Penelitian ini dilakukan di Desa yang berada dekat pesisir Kecamatan Ulujami Kabupaten Pemalang yakni 5 desa dengan total jumlah warga sebanyak 32.555 jiwa. Adapun dalam penelitian ini diambil respondensebanyak 100 respondendengan pengambilan sampel di5 desasekitar pesisir Kecamatan Ulujami Kabupaten Pemalangyakni Desa Tasikrejo, Desa Kaliprau, Desa Kertosari, Desa Blendung, Desa Limbangan dengan pengambilan data setiap desa sebanyak 20 responden. Kuesioner yang akan digunakan pada penelitian ini diujikan kepada sekelompok responden yang berjumlah 30 responden, setelah kuesioner diisi, kemudian dilihat skornya dan dihitung nilai signifikansinya. Berdasarkan tabel significancy, untuk jumlah responden sebesar 30 yaitu diperlukan nilai $r$ adalah 0,361 . Bila nilai $r$ lebih dari 0,361 maka kuesioner tersebut valid. Dalam uji validitas yang dilakukan data yang didapat untuk kuisioner tingkat pengetahuan dari 17 pernyataan yang valid hanya 7 pernyataan dan untuk pernyataan perilaku swamedika dengan 19 pernyataan didapatkan 14 pernyataan yang valid, hal ini bisa dilihat dari nilai spps yang dilakukan untuk peryataan yang tidak valid ditandai dengan nilai $r$ dibawah 0,361 .

A. Validitas Kuisioner

Validitas dilakukan pada tanggal 26 Juli 2021 di Desa Ambowetan Keacamatan Ulujami Kabupaten Pemalang, uji validitas dilakukan dengan mebagikan kuisioner kepada 30 responden masyarakat sekitar Desa Ambowetan. Hasil dari uji validitas yang telah dilakukan didapatkan hasil kuisioner tingkat pengetahuan dari 17 pernyataan 7 pernyataan valid kemudiam untuk kuisioner perilaku swamedikasi didapatkan hasil dari 19 pernyataan 14 pernytaan yang valid. 


\section{B. Reabilitas Kuisioner}

Hasil uji reabilitas didapatkan cronbach's alpha untuk tingkat pengetahuan 0,726 dan untuk nilai cronbach's alpha perilaku swamedikasi 0,838 . Syarat dari uji reabilitas adalah apabila crobach's alpha $>\mathrm{r}$ tabel $(0,361)$, sehingga dari hasil uji reabilitas tingkat pengetahuan dan perilaku swamedikasi diatas bisa dikatakan kuisioner reliabel dan dapat digunakan sebagai kuisioner untuk penelitian.

1. Jenis Kelamin

Data Karakteristik responden berdasarkan jenis kelamin dapat dilihat pada Tabel 4.1.

Tabel 4.1 Responden Berdasarkan Jenis Kelamin

\begin{tabular}{ccc}
\hline Kategori & Frekuensi & Persentase (\%) \\
\hline Laki-laki & 28 & 28 \\
Perempuan & 72 & 72 \\
\hline Total & 100 & $100 \%$
\end{tabular}

(Data Primer, 2021)

Berdasarkan karakteristik responden berdasarkan jenis kelamin pada tabel 4.1 diketahui dari 100 responden yang melakukan swamedikasi di lingkungan sekitar pesisir Kecamatan Ulujami sebagian besar responden adalah perempuan dengan jumlah persentase $72 \%$. Menurut Hungu (2016) jenis kelamin adalah perbedaan antara perempuan dengan laki-laki secara biologis sejak seorang itu dilahirkan. Perbedaan biologis dan fungsi biologis laki-laki dan perempuan tidak dapat dipertukarkan diantara keduanya, dan fungsinya tetap dengan laki-laki dan perempuan yang ada di muka bumi. Seperti pada fakta lapangan yang sering kita temui saat ini, banyak sekali tenaga kerja bagian lapangan pada umumnya didominasi oleh laki-laki, sedangkan pada bagian kantor suatu perusahaan pada umumnya didominasi oleh wanita. Hal ini sesuai dengan penelitian (Noviana, 2011) bahwa yang banyak melakukan pengobatan sendiri dan lebih memperdulikan kesehatannyasendiri maupun kesehatan keluarganya yaitu kaum perempuan dibandingkan dengan kaum pria.

2. Usia

Data karakteristik responden berdasarkan usia dapat dilihat pada Tabel 4.2.

Tabel 4.2 Responden Berdasarkan Usia

\begin{tabular}{ccc}
\hline Kategori & Frekuensi & Persentase (\%) \\
\hline $20-30$ th & 57 & 57 \\
$31-40$ th & 19 & 19 \\
$41-50$ th & 24 & 24 \\
\hline Total & 100 & 100
\end{tabular}

(Data Primer, 2021) 
Berdasarkan data karakteristik usiadiketahui bahwa rentang usia yang palingbanyak melakukan swamedikasi yakni pada usia 20 - 30 tahun sebesar 57\%. Rentang usia tersebut termasuk kedalam kategori usia masa remaja akhir sampai masa dewasa awal. Umur mempengaruhi daya tangkap dan pola pikir seseorang. Semakin bertambah umur akan semakin berkembang pula daya tangkap dan pola pikirnya, sehingga pengetahuan yang diperoleh semakin banyak (Notoatmodjo, 2003).

3. Tingkat Pendidikan

Data karakteristik responden berdasarkan tingkat pendidikandapat dilihat pada Tabel 4.3.

Tabel 4.3 Responden Berdasarkan Tingkat Pendidikan

\begin{tabular}{ccc}
\hline Kategori & Frekuensi & Persentase (\%) \\
\hline SD & 25 & 25 \\
SMA & 43 & 43 \\
SMP & 32 & 32 \\
\hline Total & 100 & 100 \\
\hline
\end{tabular}

Data yang melakukan swamedikasi di desa sekitar pesisir Kecamatan Ulujami lebih dari setengah responden memiliki tingkat pendidikan terakhir SMA sebanyak 43\%. Pendidikan adalah suatu usaha mengembangkan suatu kepribadian dan kemampuan di dalam dan diluar sekolah dan berlangsung seumur hidup. Pendidikan mempengaruhi proses belajar, semakin tinggi pendidikan seseorang semakin mudah orang tersebut menerima informasi baik dari orang lain maupun dari mediam massa. (Notoatmodjo, 2003). Berdasarkan (Supardi \&Raharni, 2006) yang dikutip oleh (Hermawati, 2012) menyatakan bahwa responden padatingkat pendidikan SMA tergolong dalam kategori pendidikan lanjutan, dalamhal ini sesuai dengan penelitiannya yang didominasi responden dengan pendidikan terakhir SMA.

4. Pekerjaan

Data karakteristik responden berdasarkan tingkat pendidikan dapat dilihat pada Tabel 4.4.

Tabel 4.4 Karakteristik Responden Berdasarkan Pekerjaan

\begin{tabular}{ccc}
\hline Kategori & Frekuensi & Persentase (\%) \\
\hline Buruh & 42 & 42 \\
Karyawan & 30 & 30 \\
Pedagang & 15 & 15 \\
Petani & 13 & 13 \\
\hline Total & 100 & 100 \\
\hline
\end{tabular}

(Data Primer, 2021) 
Berdasarkan dari data karakteristik responden dari jenis pekerjaan dapat diketahui lebih dari sebagian responden bekerja sebagai buruh42\% dan karyawan30\%. Pekerjaan menurut Thomas yang dikutip oleh Nursalam (2003), adalah kebutuhan yang harus dilakukan terutama untuk menunjang kehidupannya dan kehidupan keluarga. Pekerjaan dengan kerja fisik yang cukup tinggi seperti buruh tentu dapat menyebabkan gangguan kesehatan jadi berperluang untuk mengalami gangguan kesehatan lebih sering terutama nyeri (Fuaddah, 2015). Sehingga untuk menangani gangguan kesehatan yang dialaminya responden cenderung melakukan pengobatan sendiri atau swamedikasi.

\section{Penghasilan}

Data karakteristik responden berdasarkan penghasilan dapat dilihat pada Tabel 4.5 .

Tabel 4.5 Responden Berdasarkan Penghasilan

\begin{tabular}{ccc}
\hline Kategori & Frekuensi & $\begin{array}{c}\text { Persentase } \\
(\mathbf{\%})\end{array}$ \\
\hline$<$ RP500.000 & 28 & 28 \\
$1.500 .000-2.500 .000$ & 16 & 16 \\
$500.000-1.500 .000$ & 56 & 56 \\
\hline Total & 100 & 100 \\
\hline & \multicolumn{2}{c}{ (Data Primer,2021) }
\end{tabular}

Berdasarkan data karakteristik penghasilan responden diketahui bahwa hampir setengah responden $56 \%$ berpenghasilan antaraRp 500.000 sampai $\mathrm{Rp}$ 1.500.000. Penghasilan adalah pendapatan uang yang diterima dan diberikan kepada subjek ekonomi berdasarkan prestasi-prestasi yang diserahkan yaitu berupa pendapatan dari profesi yang dilakukan sendiri atau usaha perorangan dan pendapatan dari kekayaan. Menurut keputusan gubernur Jawa Tengah nomor 560/68tahun 2018 mengenai upah minimum di Kabupaten Pemalang tahun 2021 sejumlah Rp 1.926.000. Dalam hal tersebut tingkat penghasilan responden di Kabupaten Pemalang tergolong rendah karena di bawah angka upah minimum. Tingkat penghasilan seseorang berpengaruh terhadap sikap seseorang mengenai jenis pengobatan seseorang termasuk swamedikasi. Masyarakat dengan berpenghasilan tinggi akan mudah mengakses sarana kesehatan namun masyarakat yang berpenghasilan rendah akan cenderung menjadikan biaya sebagai pilihan utama dalam hal pencarian obat (Pangastuti, 2014).

6. Keluhan

Data karakteristik responden berdasarkan keluhan dapat dilihat pada tabel 4.6 
Tabel 4.6 Responden Berdasarkan Keluhan

\begin{tabular}{lcc}
\hline \multicolumn{1}{c}{ Kategori } & Frekuensi & Persentase (\%) \\
\hline Nyei Dada & 6 & 6 \\
Nyeri Gigi & 14 & 14 \\
Neri Haid & 8 & 8 \\
Nyeri Kaki & 5 & 5 \\
Nyeri Kepala & 29 & 29 \\
Nyeri Lambung & 1 & 1 \\
Nyeri Otot & 4 & 4 \\
Nyeri Perut & 2 & 2 \\
Nyeri Pinggang & 5 & 5 \\
Nyeri Punggung & 18 & 18 \\
Nyeri Sendi & 5 & 5 \\
Nyeri Tangan & 3 & 3 \\
\hline$\quad$ Total & 100 & 100 \\
\hline
\end{tabular}

(Data Primer, 2021)

Berdasarkan data karakteristik keluhan responden paling banyak dialami adalah nyeri kepala sebanyak 29\%. Sakit Kepala merupakan keluhan utama yang paling sering disajikan kepada dokter. Setiap jenis "sakit kepala" mempunyai dasar organik, walaupun pada sebagian terdapat juga faktor etiologik yang bersifat patogenik (Sidharta, 2012). Dalampenelitian (Ayuda, 2017) ketika mengalami nyeri kepala, tindakan yang dilakukan responden kebanyakan memilih untuk meminum obat anti nyeri, hal ini dikarenakan obat nyeri kepala bisa didapatkan dengan mudah dan tanpa resep dokter.

7. Golongan Obat dan Obat yang Digunakan

Data karakteristik responden berdasarkan keluhan dapat dilihat pada Tabel 4.7

\section{Tabel 4.7 Responden Berdasarkan Golongan Obat}

\begin{tabular}{lll}
\hline Kategori & Frekuensi & Presentase (\%)
\end{tabular}

Bebas

Bebas terbatas

Keras 
Berdasarkan data karakteristik obat yang dipilih responden untuk swamedikasi diketahui yang menggunakan obat bebas terbatas sebanyak $36 \%$, obat bebas sebanyak $27 \%$ dan keras sebanyak $37 \%$. Merk obat yang digunakan dalam penelitian ini untuk kategori obat bebas ada Paracetamol, Bodrex, Dapyrin kemudian untuk kategori obat bebas terbatas ada Feminax, Rhemachyl, Oskadon, Paramex, dan untuk kategori obat keras ada Antalgin, Asam Mefenamat, Dexamethason, Ibuprofen, Mefinal, Neuralgin, Piroxicam, Voltadex. Hasil ini sesusai dengan peraturan (Depkes, 2007) tentang pemakaian obat bebas dan obat bebas terbatas, bahwa seharusnya obat yang boleh digunakanialah obat bebas dan obat bebas terbatas.

\section{Tempat Memperoleh Obat}

Data karakteristik responden berdasarkan tempat memperoleh obat dapat dilihat pada Tabel 4.8.

Tabel 4.8 Responden Berdasarkan Tempat Memperoleh Obat

\begin{tabular}{lcc}
\hline \multicolumn{1}{c}{ Kategori } & Frekuensi & Persentase (\%) \\
\hline Apotek & 68 & 68 \\
Toko Obat & 2 & 2 \\
Warung & 30 & 30 \\
\hline Total & 100 & 100 \\
\hline
\end{tabular}

Berdasarkan data penelitian ini maka sebagian besar responden memperoleh obat di apotek sebanyak 68\%. Hal ini sesuai dengan penelitian (Rahmayanti, 2017) persentase terbanyak responden memperoleh obat di apotek, karena responden menganggap bahwa apotek adalah tempat yang tepat untuk mendapatkan obat yang terjamin kualitasnya dan banyak jenis obat yang bisa didapatkan.

9. Sumber Informasi Obat

Data karakteristik responden berdasarkan sumber informasi obat dapadilihat pada tabel 4.9

Tabel 4.9 Responden Berdasarkan Sumber Informasi Obat

\begin{tabular}{ccc}
\hline Kategori & Frekuensi & Persentase (\%) \\
\hline Apoteker/Tenaga Medis & 59 & 59 \\
Media Informasi/Elektronik & 16 & 16 \\
Tetangga & 25 & 25 \\
\hline Total & 100 & 100 \\
\hline
\end{tabular}

(Data Primer, 2021) 
Berdasarkan karakteristik responden diketahui bahwa hampir sebagian sumber informasi mengenai swamedikasi yang berasal dariApoteker /Tenaga kesehatan sebanyak 59\%. Menurut (Susilowati, 2011) peran tenaga kefarmasian (tenaga teknis kefarmasian, apoteker) sangatlah penting dalam melakukan pengobatan sendiri untuk memberikan asuhan kefarmasian. Untuk menaikkan derajat kesehatan masyarakat dan juga tepat pada penggunaan obat dikalangan masyarakat sehingga untuk mengurangi kesalahan pengobatan. Dalam hal tersebut informasi yang diterima responden yang melakukan swamedikasi sudah tepat karena hampir dari sebagian mendapatkan informasi dari tenaga kesehatan yaitu apoteker, tenaga teknis kefarmasian. Namun masih terdapat $25 \%$ informasi yang diperoleh responden dari teman/tetangga dan media informasi/elektronik hal ini dapat berisiko menyebabkan terjadinya salah dalam penggunaan obat dan salah dalam penanganannya.

\section{Tingkat Pengetahuan Swamedikasi Obat Anti Nyeri}

Tingkat Pengetahuan merupakan hasil "Tahu" dan ini terjadi sesudah seseorang melakukan pengindraan terhadap sesuatu objek tertentu. Tingkat pengetahuan memiliki beberapa subvariabel. Subvariabel ini berdasarkan pedoman obat bebas dan obat bebas. Subvariabel dalam tingkat pengetahuan meliputi pengetahuan tentang pemilihan obat sesuai gejala penyakit, pengetahuan tentang golongan obat yang dapat digunakan dalam swamedikasi, pengetahuan cara penggunaan obat dalam swamedikasi, pengetahuan tentang efek samping obat, pengetahuan tentang cara penyimpanan obat, dan pengetahuan tentang tanggal kadaluarsa obat.

Tabel 4.10 Pengetahuan Swamedikasi Obat Anti Nyeri

\begin{tabular}{ccc}
\hline Pengetahuan & Frekuensi & Persentase (\%) \\
\hline Baik & 12 & 12 \\
Cukup & 82 & 82 \\
Kurang & 5 & 5 \\
Sangat Baik & 1 & 1 \\
\hline Total & 100 & 100 \\
\hline
\end{tabular}

Berdasarkan hasil penelitian yang telah dilakukan dapat diketahui bahwa lebih dari sebagian responden $82 \%$ memiliki tingkat pengetahuan cukup. Hasil penelitian ini sejalan dengan penelitian sebelumya oleh (Hermawati, 2012) di Kecamatan Cimanggisyang menunjukkan bahwa mayoritas tingkat pengetahuan responden tergolong sedang. Namun masih terdapat sebagian kecil responden yang berpengetahuan kurang dalam hal ini dapat mengakibatkan kesalahan dalam penggunaan obat. Maka supaya tidak terjadi kesalahan dalam penggunaan obat, responden berhak mendapatkan informasi yang tepat anjuran penggunaan obat yang dibelinya. Salah satu penyebab yang membuat tingkat pengetahuan responden cukup karena sebagian responden memiliki tingkat pendidikan SMA. 


\section{E. Perilaku Swamedikasi Obat Anti Nyeri}

Berdasarkan teori Stimulus-Organisme-Respon (S-O-R) tersebut, maka perilaku manusia dapat dikelompokkan menjadi dua yaitu perilaku tertutup dan perilaku terbuka. Perilaku tertutup terjadi bila respon terhadap stimulus tersebut masih belum dapat diamati orang lain secara jelas. Respon tersebut masih terbatas dalam bentuk perhatian, perasaan, persepsi dan pengetahuan. Perilaku terbuka terjadi bila respon yang diberikan terhadap stimulus berupa tindakan atau praktik yang dapat diamati orang lain (Notoatmodjo, 2012).

Tujuan dilakukan uji normalitas karena untuk menentukan nilai cut off point dari perilaku. Pada uji normalitas perilaku yang dilakukan menggunakan uji kolmogrovsmirnov karena jumlah responden dalam penelitian lebih dari 50 responden (Sani, 2016). Berdasarkan hasil dari uji normalitas. Dalam hal ini nilai significancy dari hasil analisis menunjukkan angka 0 , hal ini berarti $>0.05$, sehingga dapat disimpulkan bahwa distribusi data perilaku responden tidak normal. Sehingga uji selanjutnya adalah uji chi square.

\section{F. Hubungan Tingkat Pengetahuan dan Perilaku Swamedikasi}

Lawrence Green (1980) menjelaskan dalam teorinya bahwa perilaku terbentuk dari tiga faktor yang meliputi faktor prediposisi (predisposing factors), faktor pemungkin (enabling factors) dan factor pendorong (renforcing factors). Faktor- faktor predisposisi terwujud dalam pengetahuan, sikap, kepercayaan, keyakinan, nilai- nilai dan sebagainya. Faktor pemungkin terwujud dalam lingkungan fisik tersedia atau tidak tersedianya fasilitas- fasilitas atau sarana-sarana kesehatan dan sebagainya. Faktor- faktor pendorong terwujud dalam sikap dan perilaku petugas kesehatan atau petugas lain (Notoatmodjo, 2012).

Diketahui hasil penelitian menyatakan bahwa dari 100 responden yang berperilaku baik sebanyak 78 responden (78\%) sedangkan responden yang memiliki perilaku sangat baik 13 responden (13\%) dan cukup sebanyak 9 responden (9\%). Dari hasil penelitian dapat diketahui tingkat pengetahuan responden di masyarakat sekitar pesisir Kecamatan Ulujami Kabupaten Pemalang sebagian besar cukup dengan total presentase 82\% dengan perbandingan nilai perilaku sangat baik 12 responden, baik 62 responden dan cukup 8 responden.

Hasil uji chi square yaitu nilai t hitung 3,343 berdasarkan hasil penelitian dapat diketahui Asmp.Sig adalah sebesar 0,765 (>0,05) maka dapat disimpulkan H1 ditolak, hal ini dapat diartikan bahwa tidak ada hubungan antara pengetahuan swamedikasi terhadap perilaku swamedikasi obat anti nyeri dikalangan masyarakat sekitar pesisir Kecamatan Ulujami Kabupaten Pemalang. Syarat dari uji chi square tabel harus 2 × 2 sehingga tabel perlu dilakukan marger yang seharusnya variabel tingkat pengetahuan responden memiliki tiga kategori hasil ukur yaitu baik, cukup, kurang namun harus ada salahsatu hasil ukur yang digabungkan atau marger dan peneliti menggabungkan hasil ukur penelitian antara cukup dan kurang. Diketahui pada tabel diatas didapatkan $\mathrm{P}$ value sebesar 3,343 yang berarti lebih kecil dari $\alpha$ 0,05 maka dapat disimpulkan bahwa $\mathrm{Ha}$ ditolak. Tidak ada hubungan yang signifikan antara tingkat pengetahuan dengan perilaku swamedikasi pengunaan obat dikalangan masyarakat sekitar pesisir Kecamatan Ulujami Kabupaten Pemalang. 


\section{KESIMPULAN}

Berdasarkan penelitian yang telah dilakukan dapat disimpulkan bahwa tidak ada hubungan antara tingkat pengetahuan dengan perilaku swamedikasi obat anti nyeri dikalangan masyarakat pesisir dengan nilai sig 0,765 $(>0,05)$, Perilaku swamedikasi obat anti nyeri responden di kalangan masyarakat sekitar pesisir Kecamatan Ulujami Kabupaten Pemalangmempunyai perilaku baik sebanyak 78\%, perilaku cukup 9\%, dan sangat baik $13 \%$, Tingkat pengetahuan responden yang melakukan swamedikasi di kalangan masyarakat sekitar pesisir Kecamatan Ulujami Kabupaten Pemalang mempunyai tingkat pengetahuan yang baik sebanyak $12 \%$, tingat pengetahuan sangat baik $1 \%$, tingkat pengetahuan cukup $85 \%$, dan tingkat pengetahuan kurang $5 \%$.

\section{DAFTAR PUSTKA}

Ali, Abdul Nazer et al. 2014. Self-medicactaion practice among health care professionals in a Private University. Malaysia: Internsioanal Current Pharmaceutical Journal, 1(10): 302-310.

Amalia Karimah. 2019.Hubungan Tingkat Pengetahuan Dengan Perilaku Swamedikasi Pasien Apotek Di Kota Pekalongan Pada Tahun 2019. Pekalongan: Universitas Muhammadiyah Pekajangan Pekalongan.

Ananda, D.A.E,. Pristianty, L,. \& Rachmawati, H. 2013 . Hubungan Tingkat Pengetahuan dan Perilaku Swamedikasi Obat Natrium Diklofenak di Apotek.Pharmacy, Vol 10 no 0.Badan Pusat Statistik. 2013. Survey Sosial Ekonomi. Jakarta: BPS.

Andarini. Purnamasari. 2012. Efektifitas Pemberian Informasi Kesehatan Reproduksi Terhadap Penurunan Perilaku Merokok pada Remaja Putri. Journal of Consulting and Clinica Psychology. Vol.74, No. 4. Yogyakarta: Universitas Mercu Biana.

Anief, M. 2010. Penggolongan Obat. 10 ${ }^{\text {th }}$. Yogyakarta: Gadjah Mada University Press 9-10.

Asyraf Vivaldi Wardoyo, Rasmi, Z.O. 2019. Tingkat Pengetahuan Masyarakat Terhadap Obat Analgesik Pada Swamedikasi Untuk Mengatasi Nyer Akut. Skripsi Makasar: Lampung University.

A, Wawan \& Dewi M. 2011. Teori dan Pengukurran, Sikap dan Perilaku Manusia. Cetakan II. Yogyakarta: Nuha Medika.

Badan Pusat Statistik [BPS]. 2016. Statistik Daerah Kecamatan Umbulharjo 2016. Badan Pusat Statistik Kota Yogyakarta.

BPOM. 2014. Menuju Swamedikasi yang Aman.Jakarta: Info POM halaman 3-5 BPS Kab. Rembang. 2016. http//rembangkab.bps.go.id/. Diakses tanggal 21 Jan 2016.

Chandra, C. H. 2016. Studi Penggunaan Obat Analgesik pada Pasien Cedera Kepala (concussion) di RSUP Prof.Dr.R.D.KANDOU Manado. Manado: Jurnal IImiah Farmasi,5(2), 197-204.

Dahuri, dkk 2011. Pengelolaan Sumber Daya Wilayah Pesisir dan Lautan Secara Terpadu (Cetakan Kedua, Edisi Revisi). Jakarta: PT. Pradnya Paramita

Farida Noviana. 2011. Artikel Kesehatan, Keselamatan, dan Keamanan Kerja http://faridanoviana.blog.perbanas.ac.id/2011/12/04/artikel-kesehatankeselamatan-dan keamanan-kerjal 
Fuaddah, A.T., 2015. Description of Self-Medication Behavior in Community of Subdistric Purbalingga, District Purbalingga. "Jurnal Kesehatan Masyarakat 3:10.

Garido, Pilar. Carasso. 2014. Precditive factors of self-medicated analgesic use in Spanish adults: a cross-sectional national study. BMC Pharmacology \& Toxicology. 20500511/15/36.

Harvey, R. A. 2013. Farmakalogi Ulasan Bergambar. Jakarta: EGC Penerbit Kedokteran.

Ikhsani, A. 2019. Perbandingan Sikap \& Swamedikasi Antara Mahasiswa Pendidikan Dokter Fak.kedokteran dan Non Kedokteran. Lampung: Skripsi Fakultas Kedokteran Universitas Lampung Bandar Lampung 7.

Lulu' Nur Afifah. 2019. Hubungan Tingkat Pengetahuan Terhadap Perilaku Swamedikasi Peneggunaan Obat Analgesik Pada Santri Tingkat MA di Pesantren Sunan Bonang Pasuruan. Skripsi Universitas Islam Negeri Maulana Malik Ibrahim Malang.

Mita, S. 2017. Pemberian Pemahaman Mengenai Penggunaan Obat analgesik secara rasional pada masyarakat di Arjasari Kab.Bandung. Bandung: Jurnal Aplikasi Ipteks Untuk Masyarakat

Notoatmodjo, s. 2012. Ilmu Perilaku Kesehatan.Jakarta: Rineka Cipta.

Nursalam, N. 2017. Metodologi Penelitian IImu Keperawatan. Jakarta: Salemba.

Pangastuti, Ratna. 2014. Edutaiment PAUD. Yogyakarta: Pustaka Pelajar.

Pratiwi, P. N., \& Liza Pristianty, G. N. 2014. Pengaruh Pengetahuan terhadap Perilaku Swamedikasi Obat Anti-Inflamasi Non-Steroid Oral pada Etnis Thionghoa Di Surabaya. Surabaya: Jurnal Farmasi Komunitas, Vol 1, Nomor 2 ; 36-42.

Priyatno, D. 2016. SPSS Hanbook: Analisis Data, Olah Data \& Penyelesaian Kasus-Kasus Statistik.Yogyakarta: Mediakom.

Putra, S. R. 2013. Buku Pintar Apoteker. Jogjakarta: Diva Press.

Riskesdas. 2013. Riset Kesehatan Dasar. Badan Peneliti dan Pengembangan Kesehatan Kementrian Kesehatan RI.

Sugiyono. 2012. Memahami Penelitian Kuantitatif, Kualitatif. Bandung: Alfabeta.

Susilowati, Yeye dan Turyanto, Tri. 2011. Reaksi Signal Rasio Profitabilitas dan Rasio Solvabilitas terhadap Return Perusahaan. Jurnal Dinamika Keuangan dan Perbankan, 3(1): h: 17-37

Syeima, Corin Nur 2010. Gambaran Pengetahuan dan Karakteristik Masyarakat RW 08 Kelurahan Pisangan Barat Ciputat tentang Pengobatan Sendiri terhadap Nyeri Menggunakan Obat Anti Nyeri. Skripsi Fakultas Kedokteran dan Ilmu Kesehatan

UIN Syarif Hidayatullah Jakarta, halaman 19-30.

Tim, Medical. Mini Notes. 2017. Basic Pharmacology and Drug Notes. Makasar: MMN Publishing.

Tjay, Hoan Tan dan Kirana Rahardja 2012. Obat-Obat Penting. Jakarta: Elex Media Komputindo, halaman 312-319.

Wardoyo, A., \& Oktarlina, R. 2019. Tingkat Pengetahuan Masyarakat Terhadap Obat Analgesik Pada Swamedikasi Untuk Mengatasi Nyeri Akut. Lampung: Jurnal

Ilmiah Kesehatan sandi Husada, 8(2), 156-160. 